\title{
Pioglitazone inhibits the proliferation and metastasis of human pancreatic cancer cells
}

\author{
ITASU NINOMIYA, KEISUKE YAMAZAKI, KATSUNOBU OYAMA, HIRONORI HAYASHI, HIDEHIRO TAJIMA, \\ HIROHISA KITAGAWA, SACHIO FUSHIDA, TAKASHI FUJIMURA and TETSUO OHTA
}

\author{
Gastroenterologic Surgery, Department of Oncology, Division of Cancer Medicine, \\ Graduate School of Medical Science, Kanazawa University, Kanazawa, Ishikawa, Japan
}

Received January 15, 2014; Accepted September 8, 2014

DOI: $10.3892 / \mathrm{ol} .2014 .2553$

\begin{abstract}
Proliferator-activated receptor- $\gamma(\operatorname{PPAR}-\gamma)$ is a nuclear receptor that acts as a transcription factor in several types of tissue. PPAR- $\gamma$ ligands are known to inhibit numerous cancer cell processes, including pancreatic cancer cell proliferation through terminal differentiation. Previous studies concerning the inhibitory effect of PPAR- $\gamma$ ligands derived from thiazolidinediones (TZDs) on the metastatic potential of cancer cells have been reported. The present study aimed to investigate whether pioglitazone, a prescription TZD class drug and a ligand of PPAR- $\gamma$, inhibits the proliferation and metastasis of pancreatic cancer cells. The inhibitory effect of pioglitazone on the proliferation of the Capan-1, Aspc-1, BxPC-3, PANC-1 and MIApaCa-2 pancreatic cancer cell lines was analyzed. Alterations in carcinoembryonic antigen (CEA), interleukin-8 (IL-8) and cyclooxygenase-2 (COX-2) mRNA expression levels subsequent to pioglitazone treatment were examined in BxPC-3 cells by quantitative reverse transcription polymerase chain reaction. In addition, whether the oral administration of pioglitazone prevents tumorigenesis and spontaneous BxPC-3 cell lymph node and lung metastases was investigated using a rectal xenograft model. Pioglitazone treatment resulted in the inhibition of proliferation in all five pancreatic cancer cell lines in vitro. Pioglitazone induced CEA mRNA expression, suppressed IL-8 and COX-2 mRNA expression in vitro, and inhibited BxPC-3 xenograft growth. Pioglitazone also reduced BxPC-3 cell lymph node and lung metastasis in the rectal xenograft model. These results suggest that pioglitazone treatment inhibited the proliferation and metastasis of pancreatic cancer cells through the induction of
\end{abstract}

Correspondence to: Dr Itasu Ninomiya, Gastroenterologic Surgery, Department of Oncology, Division of Cancer Medicine, Graduate School of Medical Science, Kanazawa University, 13-1 Takaramachi, Kanazawa, Ishikawa 920-8641, Japan

E-mail: nino@staff.kanazawa-u.ac.jp

Key words: pioglitazone, lymph node metastasis, lung metastasis, pancreatic cancer, differentiation, rectal xenograft model differentiation and the inhibition of angiogenesis-associated protein expression.

\section{Introduction}

Pancreatic ductal adenocarcinoma behaves aggressively and is an important cause of cancer-related mortality. The five-year survival rate following curative surgery has been reported to be $10-20 \%(1,2)$. Malignant pancreatic cancer cells are characterized by uncontrolled proliferation, an inability to express the differentiated features of normal duct cells and the rapid invasion of adjacent tissues (3).

Peroxisome proliferator-activated receptor- $\gamma$ (PPAR- $\gamma$ ) is a ligand-activated transcription factor that belongs to the nuclear hormone receptor super family. Patients who receive PPAR- $\gamma$-activating drugs (used to treat several million patients with type 2 diabetes mellitus) are at significantly lower risk of lung cancer (4). The activation of PPAR- $\gamma$ in non-small cell lung cancer (NSCLC) has been shown to inhibit the proliferation of NSCLC cells in vitro and in xenograft models (5-8). Thiazolidinediones (TZDs), such as pioglitazone and rosiglitazone, are a novel class of antidiabetic drugs that attenuate the insulin resistance associated with obesity, hypertension and impaired glucose tolerance in humans, as well as in several animal models of non-insulin-dependent diabetes (9). TZDs have been found to act as ligands for PPAR- $\gamma$, a member of the nuclear receptor superfamily of ligand-dependent transcription factors predominantly expressed in adipose tissue $(10,11)$. TZDs have been shown to inhibit the growth of liposarcoma (12) and breast $(13,14)$, colon (15-17), prostatic (18), gastric (19) and pancreatic (20-22) cancer. The proliferation rates of cultured breast and colon cancer cells are reduced by treatment with TZDs. The treatment also causes changes in cell morphology and gene expression that is indicative of a more differentiated state $(16,23,24)$. Consequently, PPAR- $\gamma$ has become a potential molecular target in the development of anticancer drugs, and TZDs have been submitted for use in differentiation-mediated therapy in PPAR- $\gamma$-expressing tumors. Despite promising results obtained from in vitro and in vivo studies of tumor growth following TZD treatment, few reported studies (24-26) have examined the effect of a PPAR- $\gamma$ ligand on the metastatic potential of cancer cells in an animal model and the underlying molecular mechanisms. The inhibitory effect of TZD on 
colon cancer cell metastasis has been previously demonstrated in an animal model (24) with spontaneous lymph node and hematological metastases following intra-rectal injection of tumor cells in the nude mouse rectum. The model is suitable for assessment of the antimetastatic efficacy of novel agents using quantitative polymerase chain reaction (PCR) to amplify cancer-related human $\beta$-globin DNA in the target organ (27). PPAR- $\gamma$ has been shown to be expressed in human pancreatic cancer, and TZDs have been found to inhibit pancreatic cell proliferation in vitro $(20,28,29)$. TZDs inhibit the invasiveness of pancreatic cancer (22) and pioglitazone inhibits pancreatic cancer growth in vivo (21). However, the effect of TZDs on the metastatic potential of pancreatic cancer cells remains unknown.

The present study aimed to investigate the inhibitory effect of pioglitazone on the proliferation of pancreatic cancer cell lines. In addition, the study used a rectal xenograft model to examine whether the oral administration of pioglitazone prevents tumorigenesis and the spontaneous lymph node and lung metastases of pancreatic cancer.

\section{Materials and methods}

Cell lines. Capan-1 (well-differentiated adenocarcinoma), Aspc-1 (moderately-differentiated adenocarcinoma), BxPC-3 (moderately-differentiated adenocarcinoma), PANC-1 (poorly-differentiated adenocarcinoma) and MIApaCa-2 (undifferentiated carcinoma) human pancreatic cancer cell lines were obtained from the American Type Culture Collection (Rockville, MD, USA) and cultured in RPMI 1640 medium (Nissui Pharmaceutical Co., Ltd., Tokyo, Japan) supplemented with $10 \%$ heat-inactivated fetal bovine serum (JRH Biosciences, Lenexa, KS, USA), and $100 \mathrm{U} / \mathrm{ml}$ penicillin and $100 \mu \mathrm{g} / \mathrm{ml}$ streptomycin, at $37^{\circ} \mathrm{C}$ in a humidified atmosphere of $95 \%$ air $/ 5 \% \mathrm{CO}_{2}$.

Chemicals. Pioglitazone, donated by Takeda Pharmaceutical Co., Ltd., (Tokyo, Japan), was dissolved in dimethyl sulfoxide (DMSO) and then diluted to the appropriate concentrations with culture medium. The final concentration of DMSO in the medium was $\leq 0.1 \%(\mathrm{v} / \mathrm{v})$.

Cell proliferation assay. The proliferation inhibition of pancreatic cancer cells treated with pioglitazone was determined by a standard 3-(4,5-dimethylthiazol-2-yl)-2,5-diphenyltetrazolium bromide assay. Each cell line was treated with pioglitazone at various concentrations $(0.01,0.1,1,10$ and $100 \mu \mathrm{M})$ for $48 \mathrm{~h}$. The percentage inhibition was determined by comparing the cell density of the drug-treated cells with that of the untreated control cells.

Reverse transcription (RT)-PCR. Changes in carcinoembryonic antigen (CEA), interleukin-8 (IL-8) and cyclooxygenase-2 (COX-2) mRNA expression levels subsequent to pioglitazone treatment in BxPC-3 cells were evaluated by quantitative RT-PCR. CEA is a known differentiation marker in pancreatic cancer (30). The present study also focused on IL-8 and COX-2 as angiogenic molecules. The BxPC-3 cells were cultured in medium containing $10 \mu \mathrm{M}$ pioglitazone. RNA was extracted from the cells using Isogen systems reagents (Nippon Gene
Co., Ltd., Tokyo, Japan). Subsequent to heat denaturation at $68^{\circ} \mathrm{C}$ for $15 \mathrm{~min}$ with $500 \mathrm{pmol}$ oligo(dT) primer, $10 \mu \mathrm{g}$ RNA was reverse-transcribed to first-strand cDNA at $42^{\circ} \mathrm{C}$ for $60 \mathrm{~min}$ in a reverse-transcription solution. This solution contained 400 units Moloney murine leukemia virus reverse transcriptase (Invitrogen Japan K. K., Tokyo, Japan), 50 mm Tris- $\mathrm{HCl}$ (pH 8.3), $75 \mathrm{~mm} \mathrm{KCl,} 3 \mathrm{~mm} \mathrm{MgCl}_{2}, 0.01 \mathrm{M}$ DTT, $0.5 \mathrm{~mm}$ of each dNTP and 16 units RNasin ${ }^{\circledR}$ (Promega Corporation, Madison, WI, USA) to obtain a final volume of $100 \mu \mathrm{l}$. Reverse-transcribed cDNA solution corresponding to 100 ng total RNA was amplified by quantitative PCR using a 5' nuclease assay and an ABI Prism 7700 Sequence Detector (TaqMan; PE Biosystems Japan, Tokyo, Japan). This reaction was conducted in a $50 \mu \mathrm{l}$ reaction mixture containing $200 \mathrm{nM}$ forward and reverse primers, $100 \mathrm{nM}$ probe specific for the targeted cDNA and TaqMan Universal Master mix (PE Biosystems Japan), which was comprised of Ampli-Taq Gold DNA polymerase, dNTP, dUTP, AmpErase uracil-N-glycosylase and reaction buffer. The PCR reaction was conducted using the ABI Prism 7700 Sequence Detector with thermo-cycler conditions as follows: $50^{\circ} \mathrm{C}$ for $2 \mathrm{~min}, 95^{\circ} \mathrm{C}$ for $5 \mathrm{~min}$, followed by 45 cycles of $95^{\circ} \mathrm{C}$ for $15 \mathrm{sec}$ and $60^{\circ} \mathrm{C}$ for $1 \mathrm{~min}$. The data were examined using Sequence Detection software (PE Biosystems Japan). The primers and probes for amplifying CEA, IL-8 and COX-2 mRNA were purchased from PE Biosystems Japan. Internal standard gene expression levels were examined using TaqMan GAPDH control reagents (PE Biosystems Japan). Target gene expression levels were standardized to the internal standard gene expression levels. The relative expression levels of CEA, IL-8 and COX-2 mRNA in the pioglitazone-treated BxPC-3 cells were calculated compared with the levels in the untreated cells.

Xenograft animal models. Five-week-old nude mice (BALB/ cAnNCrj-nu/nu) were obtained from Charles River Japan, Inc. (Kanagawa, Japan). Following at least one week of observation, the mice were 6-7 weeks old when the experiments were conducted. All mice were housed in the Laboratory for Animal Experiments, Research Institute, Kanazawa University School of Medicine (Kanazawa, Japan), under laminar airflow conditions. Housing was temperature-controlled with a 12-h/12-h light/dark cycle. For inoculation, log-phase BxPC-3 cells were harvested with trypsin EDTA, washed three times with RPMI and resuspended in RPMI at $1 \times 10^{7}$ cells $/ \mathrm{ml}$ density. The mice were anesthetized with ether and placed in a supine position. A 7-mm incision was made in the anterior end of the anorectal wall in the anorectal region to prevent colonic obstruction due to rectal tumor progression. The BxPC-3 tumor cells suspended in RPMI $\left(1 \times 10^{6}\right.$ cells $\left./ 0.1 \mathrm{ml} / \mathrm{mouse}\right)$ were slowly injected submucosally into the posterior wall with a 27-gauge needle. The mice received solute (DMSO) or pioglitazone (20 mg/kg/day) orally by gavage. Treatment was initiated seven days after tumor cell inoculation and was continued five times per week for five weeks. To evaluate the antitumor and antimetastatic effects of pioglitazone, the mice were sacrificed by anesthesia with pentobarbital sodium six weeks after tumor cell inoculation. The antitumor effect of pioglitazone in the primary site was evaluated by measuring the weight of the peri-anorectal tumor. To evaluate metastases, the lungs and the lymph nodes surrounding the iliac artery and abdominal 
Table I. Effect of pioglitazone on BxPC-3 xenografts ( $n=8)$.

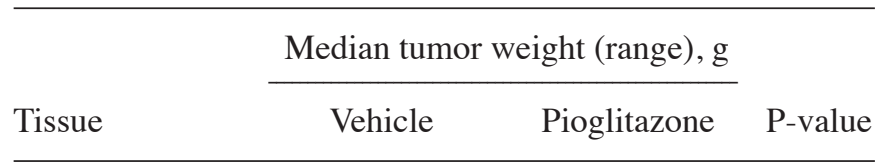

Rectal xenograft $1.67(1.23-2.18) \quad 1.38(0.67-1.74) \quad 0.046$

Statistical analysis was performed using the Mann-Whitney U test.

Table II. Antimetastatic effect of pioglitazone in the BxPC-3 rectal xenografts.

\begin{tabular}{lccc}
\hline & \multicolumn{2}{c}{$\begin{array}{r}\text { Median number of metastatic } \\
\text { BxPC3 cells (range) }\end{array}$} & \\
\cline { 2 - 3 } Target organ & Vehicle $(\mathrm{n}=8)$ & Pioglitazone $(\mathrm{n}=8)$ & P-value \\
\hline Lymph node & $7.07 \times 10^{4}$ & 0 & 0.035 \\
& $\left(0-3.29 \times 10^{5}\right)$ & $\left(0-3.57 \times 10^{4}\right)$ & \\
Lung & $4.92 \times 10^{4}$ & $2.45 \times 10^{3}$ & 0.046 \\
& $\left(0-4.65 \times 10^{5}\right)$ & $\left(0-1.73 \times 10^{5}\right)$ & \\
& & & \\
& &
\end{tabular}

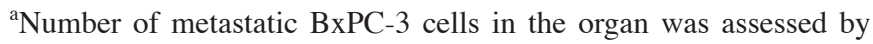
measurement of the human $\beta$-globin gene amplified by TaqMan polymerase chain reaction. Statistical analysis was conducted using the Mann-Whitney U test.

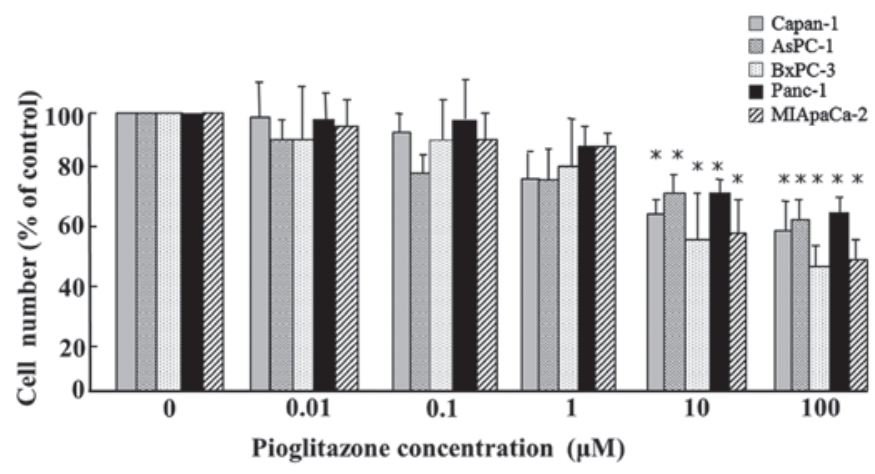

Figure 1. Effect of pioglitazone on pancreatic cancer cell proliferation. The percentage inhibition was determined by comparing the cell density of drug-treated cells to that of untreated controls. Statistical analysis was performed using Student's t-test. ${ }^{*} \mathrm{P}<0.05$ vs. untreated control.

aorta were excised. DNA from each specimen was extracted by the standard proteinase $\mathrm{K}$ digestion-phenol chloroform extraction method, as previously described (31). The human $\beta$-globin-related sequence in $1 \mu \mathrm{g}$ of each extracted DNA was amplified with primers and a probe specific for human the $\beta$-globin gene using the ABI Prism 7700 Sequence Detector (TaqMan). The concentrations of the reaction components, with the exception of template DNA and the thermo-cycler conditions, were the same as those for the aforementioned cDNA amplification. The number of metastasized tumor cells in the excised whole organ was calculated from the standard curve of a serial dilution series of BxPC-3 DNA, following quantitative PCR, as previously described (27). The primer and probe sequences for human $\beta$-globin gene amplification were as follows: Forward, CACTGACTCTCTCTGCTATTGGTC and reverse, AGGAGTGGACAGATCCCCAAA; TaqMan probe, 6FAM5'-CTACCCTTGGACCCAGAGGTTCTTTGA GTC-3'TAMRA. The study design was approved by the local ethics committee for animal experiments at the Takara-machi Campus of Kanazawa University.

Statistical analysis. The Mann-Whitney U test was used for statistical analysis of the antitumor and antimetastatic effect of pioglitazone in the xenograft model. Student's t-test was used for statistical analysis of the effect of pioglitazone on cancer cell proliferation and the alteration of mRNA expression in vitro. $\mathrm{P}<0.05$ was considered to indicate a statistically significant difference.

\section{Results}

Proliferation inhibition effect of pioglitazone in vitro. Pioglitazone significantly inhibited the proliferation of all five pancreatic cancer cell lines (Capan-1, Aspc-1, BxPC-3, PANC-1 and MIApaCa-2) in vitro at concentrations $>10 \mu \mathrm{M}$ $(\mathrm{P}<0.05$; Fig. 1).

Changes in molecular markers following pioglitazone treatment. The kinetics of $\mathrm{mRNA}$ expression subsequent to pioglitazone treatment in the $\mathrm{BxPC}-3$ cells was analyzed by quantitative RT-PCR. Exposure for $24 \mathrm{~h}$ to $10 \mu \mathrm{M}$ pioglitazone induced significant overexpression of CEA mRNA compared with that observed in the untreated cells $(\mathrm{P}<0.05$; Fig. 2A). Furthermore, $10 \mu \mathrm{M}$ pioglitazone significantly suppressed IL-8 mRNA expression after $24 \mathrm{~h}$ of exposure $(\mathrm{P}<0.05$; Fig. 2B) and COX-2 mRNA expression after $18 \mathrm{~h}$ of exposure $(\mathrm{P}<0.05$; Fig. 2C).

Antitumor and antimetastatic effects of pioglitazone in the xenograft model. Macroscopically, the BxpPC-3 xenograft produced a locally aggressive rectal tumor, and subsequently, lymph node metastases surrounding the abdominal aorta appeared six weeks after tumor cell inoculation. Pioglitazone macroscopically inhibited xenograft growth and abdominal lymph node metastasis. The antitumor activity of pioglitazone in the xenograft was examined by comparing the wet weight of each xenograft, and pioglitazone was found to significantly inhibit BxPC-3 xenograft growth by $82.6 \%(\mathrm{P}=0.046$; Table I). The antimetastatic activity of pioglitazone was examined by amplifying the human $\beta$-globin-related sequence in the lymph nodes and the lungs of rectal xenograft mice. Quantification of cancer metastasis by calculating the number of metastasized tumor cells using the quantitatively-amplified $\beta$-globin gene revealed that pioglitazone significantly inhibited lymph node and lung metastasis $(\mathrm{P}=0.035$ and $\mathrm{P}=0.046$, respectively; Fig. 3; Table II).

\section{Discussion}

In the present study, a ligand of PPAR- $\gamma$ pioglitazone inhibited pancreatic cancer cell proliferation in vitro and in vivo. Pioglitazone induced pancreatic cancer differentiation with CEA overexpression, and inhibited angiogenic factor IL-8 

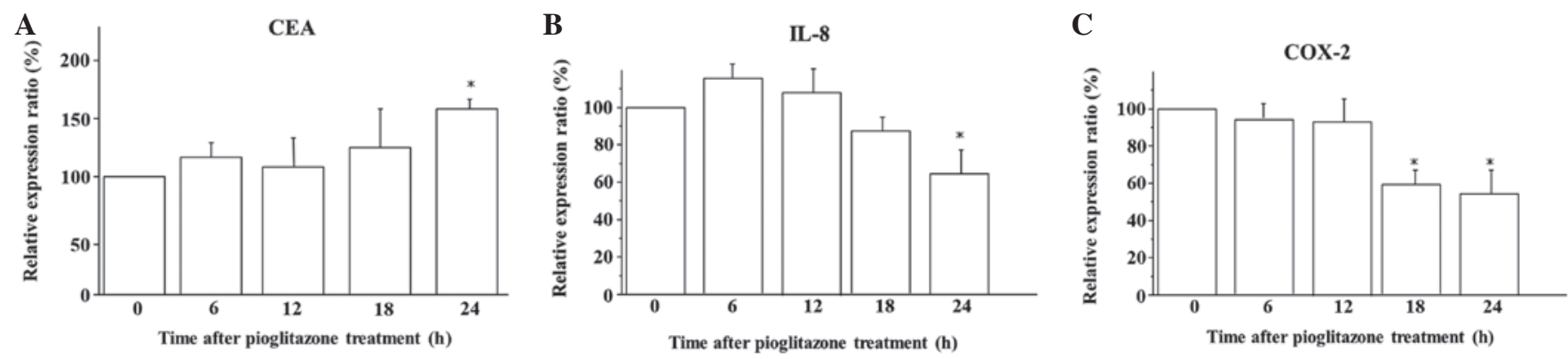

Figure 2. Kinetics of mRNA expression subsequent to pioglitazone treatment. The relative expression level ratio of (A) carcinoembryonic antigen (CEA), (B) interleukin-8 (IL-8) and (C) cyclooxygenase-2 (COX-2) mRNA in pioglitazone-treated BxPC-3 cells was calculated with respect to untreated cells. Statistical analysis was conducted using Student's t-test. $\mathrm{P}<0.05$ vs. untreated cells.

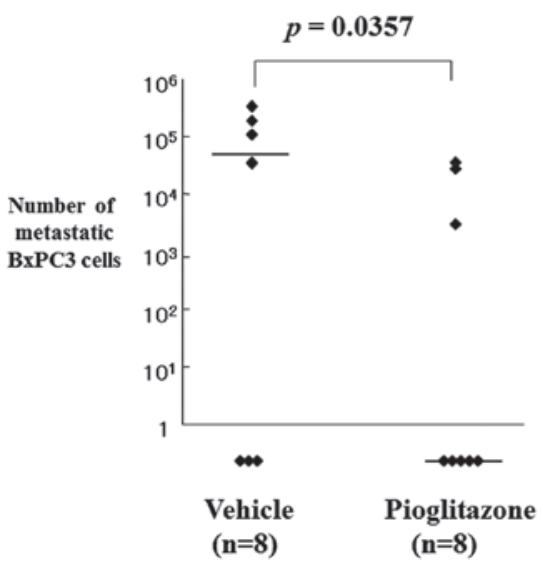

Lymph node

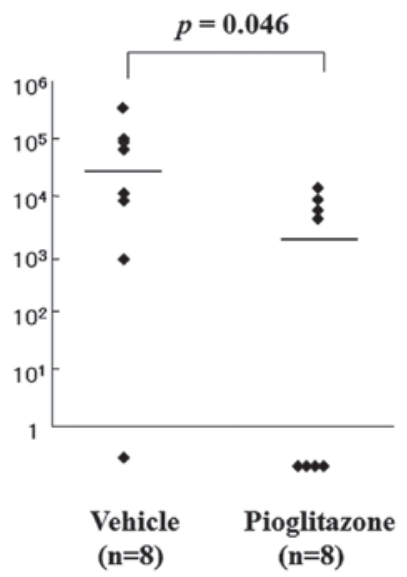

Lung

Figure 3. Comparison of metastasized tumor cell numbers in para-aortic lymph nodes and lungs of pioglitazone- and vehicle-treated mice bearing BxPC-3 pancreatic cancer cell rectal xenografts. The number of metastasized tumor cells was calculated by amplification of the human $\beta$-globin gene and is presented as the number of tumor cells in the organ. Pioglitazone significantly inhibited lymph node and lung metastases $(\mathrm{P}=0.0357$ and $\mathrm{P}=0.046$, respectively; Mann-Whitney U test).

and COX-2 mRNA expression. Furthermore, pioglitazone prevented spontaneous pancreatic cancer lymph node and lung metastases in a xenograft model.

High PPAR- $\gamma$ expression levels have been previously identified in human pancreatic cancer cells, and TZD treatment has been shown to inhibit cellular proliferation and induce cellular differentiation (20). In the present study, pioglitazone induced the upregulation of CEA mRNA expression in the BxPC-3 cells. These results indicate that pioglitazone also increased pancreatic cancer cell differentiation, as CEA expression has been previously observed to be associated with the degree of differentiation in pancreatic cancer (30). PPAR- $\gamma$ activation may also result in the differentiation of pancreatic cancer cells themselves. PPAR- $\gamma$ ligands inhibit the cellular proliferation of pancreatic cancer, a process comparable with the terminal differentiation induced by cessation of cell proliferation and the accumulation of cells in the $\mathrm{G}_{1}$ phase of the cell cycle (20). The detailed mechanism of proliferation inhibition, however, is considered to differ from cell to cell, with the exception of that caused by PPAR- $\gamma$.

In the present study, treatment with pioglitazone was demonstrated to inhibit lymph node and lung metastasis, as well as tumor growth in a rectal xenograft model. Several previous studies concerning the metastasis inhibition effect of TZDs have been published $(24,25)$. However, the underlying mechanism of metastasis inhibition by TZDs remains unclear. The data from the present study revealed that pioglitazone suppressed IL-8 and COX mRNA expression in vitro. IL-8 is commonly overexpressed in surgical specimens of pancreatic cancer tumor tissue $(32,33)$, and expression levels correlate with metastatic potential and tumor growth $(34,35)$. IL-8 promotes the growth of pancreatic tumors as a primary mediator of angiogenesis $(32,36)$, and IL-8 expression levels have been observed to correlate with angiogenesis, tumorigenicity and metastasis in numerous xenograft and orthotopic in vivo tumor models, including pancreatic cancer models (34). COX-2 is almost undetectable in the majority of tissues under normal physiological conditions (37), although it is a markedly inducible molecule that is involved in proliferation and the inflammatory response $(38,39)$. COX-2 and COX-2-derived prostaglandins have been observed to mediate tumor growth and metastasis in animal models by inducing the formation of blood vessels (40). The selective COX-2 inhibitor celecoxib has been previously reported to inhibit lung and lymph node metastasis in a colon cancer xenograft, and COX-2 inhibition by celecoxib has been observed to decrease angiogenesis, vascular endothelial growth factor expression levels and prostaglandin $\mathrm{E}_{2}$ production (41). Pioglitazone also suppresses 
COX-2 expression and inhibits the metastasis of colon cancer cells in vivo (26), and it may inhibit xenograft angiogenesis through the inhibition of IL- 8 and COX-2 mRNA expression. In conclusion, pioglitazone may inhibit metastasis by the induction of cellular differentiation and a stable cell phenotype, and by inhibition of tumor cell dissociation from the primary tumor through antiangiogenic effects.

TZD has also been demonstrated to inhibit pancreatic cancer cell invasiveness, a process that affects gelatinolytic and fibrinolytic activity with a mechanism independent of PPAR- $\gamma$ activation, which involves matrix metalloproteinase 2 and plasminogen activator inhibitor 1 expression (22). There may be several unknown mechanisms of pioglitazone-mediated metastasis inhibition. To clarify the precise mechanism of metastasis inhibition, further studies are required.

Type 2 diabetes is the most common form of diabetes and is associated with a higher risk of cancer (42). The association between diabetes and the risk of pancreatic cancer has been investigated for a long time. In addition, various preclinical and observational studies have revealed that antidiabetic medications may affect the risk of developing pancreatic cancer, although a meta-analysis of these studies did not reveal a protective or harmful association between antidiabetic therapies and the risk of pancreatic cancer in patients with diabetes (43). Recently, attention has focused on the associated between pioglitazone and an increased risk of bladder cancer. Laboratory animals have been shown to develop bladder tumors subsequent to the administration of experimental drugs with dual PPAR- $\alpha$ and PPAR- $\gamma$ activity (44). Muraglitazar, a dual human PPAR- $\alpha / \gamma$ agonist, has been found to induce a dose-related increased incidence in transitional cell papilloma and carcinoma of the urinary bladder in male rats (45). These experimental data indicate that TZDs may be a risk factor for bladder cancer in patients with diabetes, but findings from clinical and epidemiological studies are inconsistent $(46,47)$. A recent meta-analysis revealed that pioglitazone treatment appears to be associated with a significantly increased risk of bladder cancer in patients with diabetes (48). A current concern is whether the use of pioglitazone is associated with the risk of cancer. However, the association between TZD treatment and the risk of cancer remains controversial. The mechanisms underlying the pro-tumor potential of pioglitazone for bladder cancer are not yet fully understood.

As shown in the present study, pioglitazone may be useful to prevent pancreatic cancer metastases, particularly in cases of unresectable advanced disease in diabetic patients. However, careful attention is required with regard to the prophylactic use of pioglitazone following curative treatment due to the potential to induce another malignant tumor, such as bladder cancer. To confirm the usefulness of pioglitazone in pancreatic cancer treatment, clinical trials are warranted.

\section{References}

1. Matsuno S, Egawa S, Fukuyama S, et al: Pancreatic Cancer Registry in Japan: 20 years of experience. Pancreas 28: 219-230, 2004.

2. Schmidt CM, Powell ES, Yiannoutsos CT, et al: Pancreaticoduodenectomy: a 20 -year experience in 516 patients. Arch Surg 139: 718-727, 2004.
3. Höhne MW, Halatsch ME, Kahl GF and Weinel RJ: Frequent loss of expression of the potential tumor suppressor gene DCC in ductal pancreatic adenocarcinoma. Cancer Res 52: 2616-2619, 1992

4. Govindarajan R, Ratnasinghe L, Simmons DL, et al: Thiazolidinediones and the risk of lung, prostate, and colon cancer in patients with diabetes. J Clin Oncol 25: 1476-1481, 2007.

5. Choudhary R, Li H, Winn RA, et al: Peroxisome proliferator-activated receptor-gamma inhibits transformed growth of non-small cell lung cancer cells through selective suppression of Snail. Neoplasia 12: 224-234, 2010.

6. Keshamouni VG, Reddy RC, Arenberg DA, et al: Peroxisome proliferator-activated receptor-gamma activation inhibits tumor progression in non-small-cell lung cancer. Oncogene 23: 100-108, 2004.

7. Reddy RC, Srirangam A, Reddy K, et al: Chemotherapeutic drugs induce PPAR-gamma expression and show sequence-specific synergy with PPAR-gamma ligands in inhibition of non-small cell lung cancer. Neoplasia 10: 597-603, 2008.

8. Lyon CM, Klinge DM, Do KC, et al: Rosiglitazone prevents the progression of preinvasive lung cancer in a murine model. Carcinogenesis 30: 2095-2099, 2009.

9. Olefsky JM: Treatment of insulin resistance with peroxisome proliferator-activated receptor gamma agonists. J Clin Inv 106: 467-472, 2000.

10. Braissant O, Foufelle F, Scotto C, Dauça M and Wahli W: Differential expression of peroxisome proliferator-activated receptors (PPARs): tissue distribution of PPAR-alpha, -beta, and -gamma in the adult rat. Endocrinology 137: 354-366, 1996.

11. Kliewer SA, Forman BM, Blumberg B, et al: Differential expression and activation of a family of murine peroxisome proliferator-activated receptors. Proc Natl Acad Sci USA 91: 7355-7359, 1994.

12. Tontonoz P, Singer S, Forman BM, et al: Terminal differentiation of human liposarcoma cells induced by ligands for peroxisome proliferator-activated receptor gamma and the retinoid X receptor. Proc Natl Acad Sci USA 94: 237-241, 1997.

13. Mueller E, Sarraf P, Tontonoz P, et al: Terminal differentiation of human breast cancer through PPAR gamma. Mol Cell 1: 465-470, 1998.

14. Elstner E, Müller C, Koshizuka K, et al: Ligands for peroxisome proliferator-activated receptorgamma and retinoic acid receptor inhibit growth and induce apoptosis of human breast cancer cells in vitro and in BNX mice. Proc Natl Acad Sci USA 95: 8806-8811, 1998.

15. Sarraf P, Mueller E, Jones D, et al: Differentiation and reversal of malignant changes in colon cancer through PPARgamma. Nat Med 4: 1046-1052, 1998.

16. Brockman JA, Gupta RA and Dubois RN: Activation of PPARgamma leads to inhibition of anchorage-independent growth of human colorectal cancer cells. Gastroenterology 115: 1049-1055, 1998.

17. Kitamura S, Miyazaki Y, Shinomura Y, et al: Peroxisome proliferator-activated receptor gamma induces growth arrest and differentiation markers of human colon cancer cells. Jpn J Cancer Res 90: 75-80, 1999.

18. Kubota T, Koshizuka K, Williamson EA, et al: Ligand for peroxisome proliferator-activated receptor gamma (troglitazone) has potent antitumor effect against human prostate cancer both in vitro and in vivo. Cancer Res 58: 3344-3352, 1998.

19. Takahashi N, Okumura T, Motomura W, et al: Activation of PPARgamma inhibits cell growth and induces apoptosis in human gastric cancer cells. FEBS Lett 455: 135-139, 1999.

20. Elnemr A, Ohta T, Iwata K, et al: PPARgamma ligand (thiazolidinedione) induces growth arrest and differentiation markers of human pancreatic cancer cells. Int J Oncol 17: 1157-1164, 2000.

21. Itami A, Watanabe G, Shimada Y, et al: Ligands for peroxisome proliferator-activated receptor gamma inhibit growth of pancreatic cancers both in vitro and in vivo. Int $\mathrm{J}$ Cancer 94: 370-376, 2001.

22. Galli A, Ceni E, Crabb DW, et al: Antidiabetic thiazolidinediones inhibit invasiveness of pancreatic cancer cells via PPARgamma independent mechanisms. Gut 53: 1688-1697, 2004.

23. Pignatelli M, Cortés-Canteli M, Lai C, Santos A and Perez-Castillo A: The peroxisome proliferator-activated receptor gamma is an inhibitor of ErbBs activity in human breast cancer cells. J Cell Sci 114: 4117-4126, 2001 
24. Yoshizumi T, Ohta T, Ninomiya I, et al: Thiazolidinedione, a peroxisome proliferator-activated receptor-gamma ligand, inhibits growth and metastasis of HT-29 human colon cancer cells through differentiation-promoting effects. Int J Oncol 25: 631-639, 2004.

25. Panigrahy D, Singer S, Shen LQ, et al: PPARgamma ligands inhibit primary tumor growth and metastasis by inhibiting angiogenesis. J Clin Invest 110: 923-932, 2002.

26. Takano S, Kubota T, Nishibori H, et al: Pioglitazone, a ligand for peroxisome proliferator-activated receptor-gamma acts as an inhibitor of colon cancer liver metastasis. Anticancer Res 28 3593-3599, 2008

27. Ninomiya I, Terada I, Yoshizumi T, et al: Anti-metastatic effect of capecitabine on human colon cancer xenografts in nude mouse rectum. Int J Cancer 112: 135-142, 2004.

28. Motomura W, Okumura T, Takahashi N, Obara T and Kohgo Y: Activation of Peroxisome Proliferator-activated Receptor gamma by Troglitazone Inhibits Cell Growth through the Increase of p27 $7^{\mathrm{ipl}}$ in Human Pancreatic Carcinoma Cells. Cancer Res 60: $5558-5564,2000$

29. Kawa S, Nikaido T, Unno H, et al: Growth inhibition and differentiation of pancreatic cancer cell lines by PPAR gamma ligand troglitazone. Pancreas 24: 1-7, 2002.

30. Allum WH, Stokes HJ, Macdonald F and Fielding JW: Demonstration of carcinoembryonic antigen (CEA) expression in normal, chronically inflamed, and malignant pancreatic tissue by immunohistochemistry. J Clin Pathol 39: 610-614, 1986.

31. Blin N and Stafford DW: A general method for isolation of high molecular weight DNA from eukaryotes. Nucleic Acids Res 3 : 2303-2308, 1976.

32. Xie K: Interleukin- 8 and human cancer biology. Cytokine Growth Factor Rev 12: 375-391, 2001.

33. Kuwada Y, Sasaki T, Morinaka K, et al: Potential involvement of IL-8 and its receptors in the invasiveness of pancreatic cancer cells. Int J Oncol 22: 765-771, 2003

34. Shi Q, Abbruzzese JL, Huang S, et al: Constitutive and inducible interleukin 8 expression by hypoxia and acidosis renders human pancreatic cancer cells more tumorigenic and metastatic. Clin Cancer Res 5: 3711-3721, 1999.

35. Le X, Shi Q, Wang B, et al: Molecular regulation of constitutive expression of interleukin-8 in human pancreatic adenocarcinoma. J Interferon Cytokine Res 20: 935-946, 2000.

36. Koch AE, Polverini PJ, Kunkel SL, et al: Interleukin-8 as a macrophage-derived mediator of angiogenesis. Science 258 : 1798-1801, 1992.
37. Wolfe MM, Lichtenstein DR and Singh G: Gastrointestinal toxicity of nonsteroidal antiinflammatory drugs. N Engl J Med 340: 1888-1899, 1999.

38. Masferrer JL, Seibert K, Zweifel B and Needleman P: Endogenous glucocorticoids regulate an inducible cyclooxygenase enzyme. Proc Natl Acad Sci USA 89: 3917-3921, 1992.

39. Kujubu DA, Fletcher BS, Varnum BC, Lim RW and Herschman HR: TIS10, a phorbol ester tumor promoter-inducible mRNA from Swiss 3T3 cells, encodes a novel prostaglandin synthase/cyclooxygenase homologue. J Biol Chem 266: 12866-12872, 1991.

40. Masferrer JL, Leahy KM, Koki AT, et al: Antiangiogenic and antitumor activities of cyclooxygenase-2 inhibitors. Cancer Res 60: 1306-1311, 2000.

41. Ninomiya I, Nagai N, Oyama K, et al: Antitumor and anti-metastatic effects of cyclooxygenase-2 inhibition by celecoxib on human colorectal carcinoma xenografts in nude mouse rectum. Oncol Rep 28: 777-784, 2012.

42. Seshasai SR, Kaptoge S, Thompson A, et al; Emerging Risk Factors Collaboration: Diabetes mellitus, fasting glucose, and risk of cause-specific death. N Engl J Med 364: 829-841, 2011.

43. Singh S, Singh PP, Singh AG, et al: Anti-diabetic medications and risk of pancreatic cancer in patients with diabetes mellitus: a systematic review and meta-analysis. Am J Gastroenterol 108: 510-519, 2013.

44. Cohen SM: Effects of PPARgamma and combined agonists on the urinary tract of rats and other species. Toxicol Sci 87: 322-327, 2005 .

45. Tannehill-Gregg SH, Sanderson TP, Minnema D, et al: Rodent carcinogenicity profile of the antidiabetic dual PPAR alpha and gamma agonist muraglitazar. Toxicol Sci 98: 258-270, 2007.

46. Lewis JD, Ferrara A, Peng T, et al: Risk of bladder cancer among diabetic patients treated with pioglitazone: interim report of a longitudinal cohort study. Diabetes Care 34: 916-922, 2011.

47. Ferrara A, Lewis JD, Quesenberry CP Jr, et al: Cohort study of pioglitazone and cancer incidence in patients with diabetes. Diabetes Care 34: 923-929, 2011.

48. Zhu Z, Shen Z, Lu Y,Zhong S and Xu C: Increased risk of bladder cancer with pioglitazone therapy in patients with diabetes: A meta-analysis. Diabetes Res Clin Pract 98: 159-163, 2012. 